\title{
Width of attached gingiva in an Indian population: A descriptive study Shaju Jacob $P^{l}$, Zade RM ${ }^{2}$
}

\begin{abstract}
$\underline{\text { Abstract }}$
Objectives: Attached gingiva is important for maintaining periodontium in a healthy state. The present study tries to find the normal values of width of attached gingiva in a periodontally healthy Indian population. Material and Methods: The width of attached gingiva was measured with a periodontal probe in periodontally healthy patients attending the periodontics department. Descriptive statistical analysis was done to get the mean, which will represent the normal values of width of attached gingiva for the population. Results: Female patients had a greater width than males and the 20 to 30 year old group had the greatest width of attached gingiva. The mean values of attached gingiva varied in different areas of the mouth with greatest width in maxillary central incisors and least in mandibular molars. Conclusion: Width of attached gingiva varies with age, gender and in different areas of the mouth.
\end{abstract}

Key words: Periodontium, gingiva, health,

\section{Introduction:}

Attached gingiva is one of the most important anatomic and functional landmarks in the periodontium. Though there is not enough evidence on the role of attached gingiva in maintaining psence of the attached gingiva can lead to inflammation in individuals with less than optimal plaque control ${ }^{1}$. Creation of an increasing the width of attached gingiva forms a major portion of periodontal plastic surgery. There are very few studies done to evaluate the width of attached gingiva and no studies on the Indian population. Assessing the width of the attached gingiva will help in assessing the risk for a periodontium to be affected by disease for which normal values need be known for that population. The study was aimed to assess the width of attached gingiva in the population attending the dental college in Chhattisgarh.

1. Dr. Shaju Jacob P, Department of Periodontics and Oral Implantology

2.Prof. Zade RM ,Dean, Chhattisgarh Dental College and Research Institute

\section{Corresponds to:}

Dr. Shaju Jacob P, Reader, Department of Periodontics and Oral Implantology

Chhattisgarh Dental College and Research Institute, Rajnandgaon, Chhattisgarh. INDIA.

Email: shajujacob@yahoo.com 
Materials and Methods:

Patients attending the periodontal Outpatient department in the age group of 20 to 50 years were invited to participate in the study. Patients with more than $4 \mathrm{~mm}$ of Clinical attachment level in any of the assessed teeth were excluded. As there was no probing of gingiva involved, no medical contraindication for inclusion criteria was kept. Institutional Ethics

Committee gave approval for the study. After getting informed consent, patients' data were collected through an administered questionnaire and clinical examination. Attached gingiva was measured by the following way with a UNC 15 periodontal probe. The distance from the crest of marginal gingiva to mucogingival junction is measured and is subtracted with the probing depth in the mid buccal region to get the width of attached gingiva on the buccal side of all the central incisors, first premolars and first molars, a total of 12 teeth.

\section{Results:}

A total of 73 patients participated in the study of which $43(59 \%)$ were females. Female patients had a higher width of 3.04 $\mathrm{mm}$ than males with an average of 2.67 $\mathrm{mm}$ (Table 1). Maxillary central incisors had the greatest width with an average of $3.77 \mathrm{~mm}$ and mandibular molars had the least width of $2.48 \mathrm{~mm}$ (Table 2). Mandibular incisors had a width of 2.52 $\mathrm{mm}$, maxillary premolars $3.04 \mathrm{~mm}$, mandibular premolars $2.75 \mathrm{~mm}$ and maxillary molars $2.58 \mathrm{~mm}$. Width of a gingiva was the looked in to in different age groups. In the age group of 20-30 year the width was found to be greatest, 2.97 $\mathrm{mm}$ while $30-40$ year olds patients had the lowest of $2.721 \mathrm{~mm}$. The greatest width was seen in a left maxillary premolar and the lowest value was $0 \mathrm{~mm} \quad(0 \mathrm{~mm}$ indicates absence of attached gingiva) found in all categories of teeth.

Table 1: Width of Attached gingiva in Males and Females

\begin{tabular}{|l|c|c|}
\hline & $\mathrm{N}$ & Mean $\pm \mathrm{SD}(\mathrm{mm})$ \\
\hline Female & 43 & $3.035 \pm 1.269$ \\
\hline Male & 30 & $2.674 \pm 1.536$ \\
\hline
\end{tabular}

Table 2: Width of Attached gingiva among different types of tooth

\begin{tabular}{|l|c|}
\hline Tooth type & Mean \pm SD (mm) \\
\hline Maxillary central incisors & $3.771 \pm 1.761$ \\
\hline Maxillary first premolars & $3.044 \pm 1.929$ \\
\hline Maxillary first molars & $2.578 \pm 1.581$ \\
\hline Mandibular central incisors & $2.516 \pm 1.370$ \\
\hline Mandibular first premolars & $2.752 \pm 1.730$ \\
\hline Mandibular first molars & $2.480 \pm 1.273$ \\
\hline
\end{tabular}


Table 3: Width of attached gingiva in different age groups

\begin{tabular}{|l|c|c|}
\hline Age group in years & $\mathrm{N}$ & $\begin{array}{c}\text { Mean } \pm \text { SD } \\
(\mathrm{mm})\end{array}$ \\
\hline $20-30$ & 39 & $2.97 \pm 1.34$ \\
\hline $30-40$ & 14 & $2.72 \pm 1.63$ \\
\hline $40-50$ & 20 & $2.85 \pm 1.35$ \\
\hline
\end{tabular}

\section{Discussion:}

There are very studies done on the width of attached gingiva. One of the most often study quoted on width is by Bowers ${ }^{2}$ GM in 1963 and Ainamo $^{3}$ in 1976. The present study measured attached gingiva with the help of a periodontal probe similar to Tenenbaum ${ }^{4}$ while Talari ${ }^{5}$, Ainamo ${ }^{6}$ and Saario $^{7,8}$ used Schiller's iodine solution and orthopantomograms to measure. Bowers ${ }^{2}$ found the facial attached gingiva varied in different areas of the mouth as seen in the present study. Ainamo ${ }^{3}$ found greatest in maxillary incisors similar to our study. The least width in our study was in mandibular molars while Ainamo ${ }^{3}$ found it to be mandibular premolars. Ainamo ${ }^{3}$ and Vincent ${ }^{9}$ found the width of attached gingiva increases with age where as our study found width was greatest in the 20-
30 age group while the middle age group of 30-40 years was the least (Table3).

\section{Conclusion:}

Width of attached gingiva varies in different areas of the mouth with the maxillary incisors having the greatest width. There was no relationship with age while females had a greater width of attached gingiva. Further studies should be done on periodontally healthy individuals in different population in India to get a reference value for width of attached gingiva.

\section{Acknowledgements:}

I like to thank the students and management of Chhattisgarh Dental College and Research Institute for the support and help rendered towards conduct of the above study.

\section{Reference:}

1. H.H.Takei, R.R.Azzi, T.J.Han. Periodontal Plastic and Esthetic Surgery. In Newman MG, Takei HH, Klokkevold PR, Carranza FA Eds Carranza's Clinical Periodontology, 10 ${ }^{\text {th }}$ ed.. 2006: 1005-1029.
2. Bowers GM. A study of the width of the attached gingiva. J Periodontology, 1963; 34:210-13.

3. Ainamo J, Talari A. The increase with age of the width of attached gingiva. $J$ Periodontal Res 1976; 11:182-88. 
4. Tenenbaum H, Tenenbaum M. A clinical study of the width of the attached gingiva in the deciduous, transitional and permanent dentitions. J Clin Periodontol 1986; 13(4):270-75.

5. Talari A, Ainamo J. Orthopantomographic assessment of the width of attached gingiva. $J$ Periodontal Res 1976; 11(4):177-81.

6. Ainamo A, Ainamo J. The width of attached gingiva on supraerupted teeth. J Periodontal Res 1978; 13(3):194-98.
7. Saario M, Ainamo A, Mattila K, Suomalainen K, Ainamo J. The width of radiologically-defined attached gingiva over deciduous teeth. $J$ Clin Periodontology 1995; 22(12):895-98.

8. Saario M, Ainamo A, Mattila K, Ainamo J. The width of radiologicallydefined attached gingiva over permanent teeth in children. $J$ Clin Periodontology 1994; 21(10):666-69.

9. Vincent JW, Machen JB, Levin MP. Assessment of attached gingiva using the tension test and clinical measurements J Periodontology 1976; 47(7): 412-14. 